Received Date : 20-Nov-2014

Revised Date : 05-Feb-2015

Accepted Date : 05-Feb-2015

Article type : Forum Article

Editor : Jacqueline Frair

\title{
Ecologists need robust survey designs, sampling and analytical methods
}

Matt W. Hayward ${ }^{1}$, Luigi Boitani ${ }^{2}$, Neil D. Burrows ${ }^{3}$, Paul J. Funston ${ }^{4}$, K. Ullas Karanth ${ }^{5}$, Darryl I. MacKenzie ${ }^{6}$, Ken H. Pollock ${ }^{7}$, Richard W. Yarnell ${ }^{8}$

${ }^{1}$ School of Environment, Natural Resources and Geography, Bangor University LL572UW Gwynedd, Wales, U.K.; Centre for Wildlife Management, University of Pretoria \& Centre for African Conservation Ecology, Nelson Mandela Metropolitan University, South Africa m.hayward@bangor.ac.uk

${ }^{2}$ Department of Biology and Biotechnologies, Sapienza University of Rome, Viale Università 32, 00185 Roma, Italy.

${ }^{3}$ Senior Principal Research Scientist, Science and Conservation Division, Department of Parks and Wildlife, Kensington, Western Australia, 6151.

${ }^{4}$ Senior Director Lion Program, Panthera, 8 West 40th Street, 18th Floor, New York, NY 0018 USA.

${ }^{5}$ Director for Science-Asia, Wildlife Conservation Society, 1669, 31st Cross, 16th Main Banashankari 2nd Stage, Bangalore (Bengaluru), Karnataka - 560070 India

${ }^{6}$ Proteus Wildlife Research Consultants, Dunedin, New Zealand.

${ }^{7}$ Department of Applied Ecology, North Carolina State University, Raleigh NC USA 276957617

This article has been accepted for publication and undergone full peer review but has not been through the copyediting, typesetting, pagination and proofreading process, which may lead to differences between this version and the Version of Record. Please cite this article as doi: 10.1111/1365-2664.12408

This article is protected by copyright. All rights reserved. 
${ }^{8}$ School of Animal, Rural and Environmental Sciences, Nottingham Trent University, Brackenhurst Campus, Southwell, NG250QF U.K.

Running head: Robust methods in ecology

\section{Summary}

1. Research that yields conflicting results rightly causes controversy. Where methodological weaknesses are apparent, there is ready opportunity for discord within the scientific community, which may undermine the entire study.

2. We use the debate about the role of dingoes Canis dingo in conservation in Australia as a case study for a phenomenon that is relevant to all applied ecologists, where conflicting results have been published in high quality journals and yet the problems with the methods used in these studies have led to significant controversy.

3. To alleviate such controversies, scientists need to use robust methods to ensure that their results are repeatable and defendable. To date, this has not occurred in Australia's dingo debate due to the use of unvalidated indices that rely on unsupported assumptions.

4. We highlight the problems that poor methods have caused in this debate. We also reiterate our recommendations for practitioners, statisticians and researchers to work together to develop long-term, multi-site experimental research programmes using robust methods to understand the impacts of dingoes on mesopredators.

5. Synthesis \& applications. Incorporating robust methods and appropriate experimental designs are needed to ensure that conservation actions are appropriately focused and are supported with robust results. Such actions will go a long way towards resolving the debate about the role of dingoes in conservation in Australia, and other, ecological debates.

Keywords: indices, ecological methods, scientific debates, occupancy modelling, detectability, robust survey methods, dingo debate, predator interactions, intraguild interactions

This article is protected by copyright. All rights reserved. 


\section{Introduction}

Experimentation at sufficient sites and scales, coupled with robust methods, are fundamental to scientific advancement. Without these key features, the scientific method fails and scientific conflict arises. Weaknesses in the science associated with controversial management activities can undermine the entire scientific and management process, so clearly robust scientific methods are critically important (Stephens et al. 2015).

Debates within the ecological literature regularly arise, and here we use the dingo Canis dingo in Australia to illustrate that an applied ecological controversy could be resolved if robust methods and appropriate experimental manipulations are used. An advance in statistical analysis led Johnson \& VanDerWal (2009) to show the negative relationship between the upper limit of indices of fox 'activity' with that of dingoes. Since then, participants in this debate have regularly called for robust methods and statistical analysis in studying the interactions between predators (e.g. Allen 2010; Johnson et al. 2014). Yet, when Hayward \& Marlow (2014; hereafter 'H\&M') called for the use of advanced statistical methods to account for clear biases in the most widely used data collection method in the dingo-fox-cat debate in Australia (unvalidated indices of activity or abundance based on footprints on sand pads on trails), others argued that existing methods are good enough (Nimmo et al. 2015).

The response to H\&M suggests some confusion. H\&M specifically did not caution against incorporating dingoes into conservation programmes (as suggested by Nimmo et al. 2015). Rather, H\&M cautioned against drawing conclusions about the role of dingoes in conservation programs given the conflicting evidence. They had an entire section titled "Dingoes have value irrespective of their mesopredator-suppressive role" and recommended that practitioners should be involved in testing dingo-mesopredator interactions through "planning and implementing innovative, ideally randomized, management manipulations". H\&M highlighted that practitioners have already begun this kind of critical research at Arid Recovery in South Australia (Moseby et al. 2012) and at Rangelands Restoration in Western Australia (Dunlop \& Morris 2009).

This article is protected by copyright. All rights reserved. 
The driver of the H\&M paper was an attempt to explain how two groups of independent scientists could obtain opposing results using the same or similar methodologies, often in the same locations. While these two groups have debated the validity of each other's results, $H \& M$ contended that, perhaps, their conflicting results were an artefact of the sampling methods used - namely footprint or track counting as an indirect measure of abundance. Unless it is properly validated for each circumstance, this method is unreliable for numerous reasons (Buckland et al. 2001; Wilson \& Delahay 2001; MacKenzie et al. 2006), largely because it ignores problems with detectability. H\&M highlighted these problems, then argued for the use of large-scale experimentation to test the effect of dingoes on mesopredators and prey species using robust methods that accounted for detectability. Here, we build on those arguments, further illustrating the importance of using robust methods, highlighting the problems arising from inferences drawn from the use of indices of abundance, and providing a rationale for the future collaborative, large-scale, multi-site experimental manipulations that are necessary to settle the debate about the role of dingoes in controlling mesopredators in Australia.

\section{Robust methods reduce conjecture and erroneous conclusions in ecology}

If all studies had drawn the same conclusion regarding the impact of dingoes on mesopredators, there would be no debate and conservation action would have been taken. Instead, we are required to defend our suggestion that ecologists studying this problem should use techniques that account for differential detectability and represent the most robust techniques available to ecologists faced with such problems. Owing to the challenging assumptions and 'prohibitively' large data requirements of these robust methods, Nimmo et al. disregard their utility, despite the facts that: (i) the same assumptions are generally made of indices of abundance; and (ii) a failure to meet the data requirements of more robust methods usually results in a reliance on alternative, scant and unreliable data (Buckland et al. 2001; MacKenzie et al. 2006). Nimmo et al. are not alone in suggesting that detectability is unimportant: just $23 \%$ of 537 ecological articles accounted for imperfect detection, even though $86 \%$ of studies that tested for stable detectability showed significant variation (Kellner \& Swihart 2014).

Nimmo et al. state that "track indices of carnivores often perform well" and give examples of when they have worked (e.g. Stander et al. 1997; Funston et al. 2010). We agree

This article is protected by copyright. All rights reserved. 
that track indices can and do reflect true relative abundance in certain circumstances (but see Midlane et al. 2015). However, this does not legitimise a widespread reliance on track indices. Here, we focus on two interrelated problems that suggest that the 'often' referred to by Nimmo et al. is far from always.

(1) Indices require repeated validation but validation is difficult. An index is a statistic that we assume to be in some way correlated to the true parameter of interest. Typically, indices are assumed to show a monotonic relationship with the variables they index and, in general, a linear relationship is assumed. This is very rarely tested, however, and it is very difficult to validate an index against a true abundance, because of sampling variation in both the abundance and the index (Rotella \& Ratti 1992). Gopalaswamy et al. (2015) illustrate that such validation will yield poor inferences unless all the sampled parameters lie within a limited range, potentially leading to an enormous waste of resources for little gain in ecological inference.

Relationships between indices and abundance must be verified with independent data. Many factors (including those associated with the environment, observers, animal movements and animal status) can influence those relationships, so verification is context specific and must be repeated at the appropriate local, temporal and spatial scales each time the index is used. For this reason, approaches that simultaneously estimate abundance and detectability, such as occupancy approaches, should be preferred over indices.

Given these considerations, the reliability of track indices as a surrogate for population density is understandably context dependent. For example, the method of Funston et al. (2010) is only recommended in the context of clay-based soils and studies elsewhere need to revalidate the method prior to its use. Karanth et al. (2003) illustrated why the effect of context undermines the use of track surveys for tigers Panthera tigris, and similar problems have been identified for a range of other species (Dyke, Brocke \& Shaw 1986; Stanley \& Bart 1991). More recent work has suggested that indices of tiger sign might usefully predict abundance (Jhala, Qureshi \& Gopal 2011). However, recent reanalysis casts doubt on these results, showing that several parameters (including detection probability) cannot be controlled for in calibrating indices, and these dictate both the outcome of calibration and the resultant predictions (Gopalaswamy et al. 2015).

This article is protected by copyright. All rights reserved. 
To provide confidence in the use of indices in the dingo debate, the work of Stander et al. (1997) and Funston et al. (2010) is exactly the kind of research that needs to be done on dingoes, foxes and cats. This work needs to be conducted at a range of sites with different tracking substrates and in a range of weather conditions (given the impact of wind and rain on tracking substrate and track persistence). Validation work should also cover different predator control scenarios, in areas where reinvasion is an ever-present problem.

(2) Calibration is not constant across contexts. Even where an index has been validated and shown to have a particular relationship with the underlying variable of interest, that index cannot be applied with confidence, either to different species in the same locale, or to the same species in different areas. Comparing indices (e.g. those derived from different modes of data collection or between different species), requires very restrictive and unrealistic assumptions (Williams, Nichols \& Conroy 2002). For example, indices can only be compared with themselves in time or space assuming all other variables remain unchanged, which is highly unlikely.

Much of the evidence in the dingo-fox-cat debate comes from comparisons between paired (but unreplicated) study sites, where control of dingoes occurs in one of the paired sites. However, comparisons of track indices of a given carnivore species between sites are unreliable due to differences in habitat type, substrate, season, and local weather (Wilson \& Delahay 2001). Thus, the indices will have different relationships with underlying abundances. Even in single site temporal studies, track indices of carnivore abundance should be used with caution to monitor the impacts of control, especially if control causes a change in the ranging behaviour, resulting in a change in the index unrelated to population size (Wilson \& Delahay 2001). Concluding that there is a negative relationship between the abundance of dingoes and feral cats based on trends in the track counts of each species is unsupportable because of the variety of other factors that can influence the number of tracks and track counting.

One particular issue that can confound attempts to relate indices of abundance of two different species to each other arises where one species influences the behaviour of another. One mechanism for this among carnivores is where one species influences the use of trails by another. H\&M argued that that the preferential use of trails by apex predators, and their avoidance by mesopredators, are well-documented (Thurber et al. 1994; Henschel \& Ray

This article is protected by copyright. All rights reserved. 
2003; Whittington, St. Clair \& Mercer 2005; Larrucea et al. 2007; Harmsen et al. 2009;

Cheyne et al. 2010; Burton et al. 2012; Guthlin et al. 2012; Whittington-Jones et al. 2014), but Nimmo et al. contested the ubiquity of this behavioural pattern. Assuming this pattern to be typical is just as risky as assuming that both apex and mesopredators maintain their "normal" use of trails under different landscape contexts; the point of agreement should be the need to admit our working assumptions and challenge them with robust data.

Overall, indices of predator abundance, such as track or footprint counts, are appealing because they are relatively inexpensive and easy to collect. However, choosing between indices and population estimates should not be driven by feasibility but by research objectives, desired confidence in the results and the limitations imposed by each method. Indices are problematic for making costly and delicate management decisions (Williams, Nichols \& Conroy 2002; Long et al. 2008) and, even worse, may distract from the objectives of the focal research. For example, Nimmo et al. contend that, irrespective of the known biases of the index method, it is the response of native fauna that is important. They observe that "a reduction in mesopredator predation on native mammals (due to suppression of dingo density) is sufficient at least to offset any direct predation by dingoes, resulting in higher abundances of native species in the presence of dingoes". Yet this suggests no change in net predation rates, which would not deliver an improvement in the status of threatened species. Importantly, if the response of (particularly threatened) native fauna is the key variable, then predator activity is of secondary importance. Instead, the focus should be on robust methods to estimate the change in population density of native fauna between treatments. Nimmo et al. cite studies that purport to show the benefits of dingoes for fauna conservation but other studies reached different conclusions (e.g. Arthur, Catling \& Reid 2012; Allen et al. 2014). The lack of consistent results illustrates why this controversy arose and reinforces the need for robust methods and experimental design to remove it.

\section{The way forward}

Robust experimental design is critical to making strong inferences about this debate. Informative manipulations need to be conducted at large spatial and temporal scales. The necessary replicated and controlled experiments are likely to need contiguous habitats where management can manipulate the abundance of dingoes, foxes and cats, while monitoring the

This article is protected by copyright. All rights reserved. 
density of key prey resources. The scales necessary are very large given the home range size of these species; however, sites like Lorna Glen (244 000 ha; Western Australia), Arid Recovery (32 300 ha; South Australia), and Sturt National Park (310 600 ha; New South Wales) are ideal candidate study areas. Long-time frames (several years) should also be incorporated to ensure that the confounding effects of variability in bottom-up factors can be accounted for. The manipulations could either entail experimental control or reintroduction of dingoes and intensive monitoring of mesopredators via camera trapping on and off trails for occupancy analysis or population estimation via the random encounter model (Rowcliffe $e t$ al. 2008), coupled with telemetry to measure their behavioural responses. Although challenging, large-scale experimental manipulations have occurred elsewhere around the world to solve similarly controversial issues (Western Shield fox control program: Possingham, Jarman \& Kearns 2004; Randomised Badger Culling Trial: Donnelly et al. 2006; Large-scale effects of predator control in North America: Hurley et al. 2011).

Perhaps more challenging is that the required large-scale, long-term experiments will need spatial replication across regions, and this will entail multiple agencies utilising common survey designs and robust, quantitative methods. Such multi-agency collaboration is rare in Australia, but is essential to derive the answers necessary to end this debate. Although addressing the dingo debate with large-scale, robust experimental designs and coordinated replications will carry a non-trivial expense, the conservation implications of their effective removal or inclusion in conservation plans could more than recoup these costs in the long run. Furthermore, applied ecologists must continually highlight that environmental management and policy require the strongest possible science (Stephens et al. 2015) and seek appropriate funding to achieve this.

\section{Conclusion}

As in the H\&M paper, we conclude here by suggesting researchers and practitioners work together with statisticians and quantitative biologists to conduct the large-scale experiments necessary to inform this debate. In our experience, this is not standard practice within applied ecological studies, but would yield clear benefits to the outcomes. Without robust methods, experimental design and data, there will be on-going speculation, claim and counter-claim about the conservation merits or otherwise of dingoes in the Australian environment

This article is protected by copyright. All rights reserved. 
(Claridge 2013). It is encouraging that the conclusion that large scale experiments are required is shared by both $\mathrm{H} \& \mathrm{M}$ and Nimmo et al., although $\mathrm{H} \& \mathrm{M}$ also recommend robust methods involving intensive monitoring. Indeed, excluding misrepresentations, the use of robust methods seems the only area of disagreement between Nimmo et al. and H\&M.

The apparent ease of recording indices (e.g. tracks) may be misleading, because of the substantial additional work required to interpret the index, or to validate it as a reliable measure of relative abundance across a range of conditions. It is hard to learn much from methods with big and unmeasured uncertainty that can vary in either direction. It is also worth remembering that the situation in Australia is somewhat unique: the predators in question (canids and felids) are introduced, so the usual evolved relationships between predators, mesopredator release theory and prey species, may not apply.

\section{Acknowledgements}

We thank Jacqueline Frair, Steve Buckland, Scott Creel, Sarah Durant, Mick McCarthy and an anonymous referee for providing valuable comments on earlier drafts.

\section{Data Accessibility}

Data have not been archived because this article does not contain data.

\section{References}

Allen, B.L. (2010) Did dingo control cause the elimination of kowaris through mesopredator release effects? A response to Wallach and O'Neill (2009). Animal Biodiversity and Conservation, 33, 205-208.

Allen, B.L., Allen, L.R., Engeman, R.M. \& Leung, L.K.P. (2014) Sympatric prey responses to lethal top-predator control: predator manipulation experiments. Frontiers in Zoology, 11, 56.

Arthur, A.D., Catling, P.C. \& Reid, A. (2012) Relative influence of habitat structure, species interactions and rainfall on the post-fire population dynamics of ground-dwelling vertebrates. Austral Ecology, 37, 958-970.

This article is protected by copyright. All rights reserved. 
Buckland, S.T., Anderson, D.R., Burnham, K.P., Laake, J.L., Borchers, D.L. \& Thomas, L.N. (2001) Introduction to Distance Sampling: Estimating Abundance of Biological Populations. Oxford University Press, Oxford.

Burton, A.C.O., Sam, M.K., Balangtaa, C. \& Brashares, J.S. (2012) Hierarchical multispecies modelling of carnivore responses to hunting, habitat and prey in a West African Protected Area. PLoS ONE, 7, e38007.

Cheyne, S.M., Husson, S.J., Chadwick, R.J. \& Macdonald, D.W. (2010) Diversity and activity of small carnivores of the Sabangau Peat-swamp Forest, Indonesian Borneo. Small Carnivore Conservation, 43, 1-7.

Claridge, A.W. (2013) Examining interactions between dingoes (wild dogs) and mesopredators: the need for caution when interpreting summary data from previously published work. Australian Mammalogy, 35, 248-250.

Donnelly, C.A., Woodroffe, R., Cox, D.R., Bourne, F.J., Cheeseman, C.L., Clifton-Hadley, R.S., Wei, G., Gettinby, G., Gilks, P., Jenkins, H., Johnston, W.T., Le Fevre, A.M., McInerney, J.P. \& Morrison, W.I. (2006) Positive and negative effects of widespread badger culling on tuberculosis in cattle. Nature, 439, 843-846.

Dunlop, J. \& Morris, K.D. (2009) Into the wild: restoring rangeland fauna. Landscope, 24, $18-24$.

Dyke, F.G.V., Brocke, R.H. \& Shaw, H.G. (1986) Use of Road Track Counts as Indices of Mountain Lion Presence. The Journal of Wildlife Management, 50, 102-109.

Funston, P.J., Frank, L.G., Stephens, T., Davidson, Z., Loveridge, A.J., Macdonald, D.W., Durant, S.M., Packer, C., Mosser, A. \& Ferreira, S.M. (2010) Substrate and species constraints on the use of track incidences to estimate African large carnivore abundance. Journal of Zoology, 281, 56-65.

Gopalaswamy, A., Delampady, M., Karanth, K.U., Kumar, N.S. \& Macdonald, D.W. (2015) An examination of index-calibration experiments: counting tigers at macroecological scales. Methods in Ecology and Evolution, In press.

Guthlin, D., Kroschel, M., Kuchenhoff, H. \& Storch, I. (2012) Faecal sampling along trails: a questionable standard for estimating red fox Vulpes vulpes abundance. Wildlife Biology, 18, 374-382.

Harmsen, B.J., Foster, R.J., Silver, S.C., Ostro, L.E.T. \& Doncaster, C.P. (2009) Spatial and temporal interactions of sympatric jaguars (Panthera onca) and pumas (Puma concolor) in a neotropical forest. Journal of Mammalogy, 90, 612-620.

This article is protected by copyright. All rights reserved. 
Hayward, M.W. \& Marlow, N.J. (2014) Will dingoes really conserve wildlife and can our methods tell? Journal of Applied Ecology, 51, 835-838.

Henschel, P. \& Ray, J.C. (2003) Leopards in African Rainforests: Survey and Monitoring Techniques., pp. 50. Wildlife Conservation Society, New York.

Hurley, M.A., Unsworth, J.W., Zager, P., Hebblewhite, M., Garton, E.O., Montgomery, D.M., Skalski, J.R. \& Maycock, C.L. (2011) Demographic response of mule deer to experiemental reduction of coyotes and mountain lions in southeastern Idaho. Wildlife Monographs, 178, 1-33.

Jhala, Y.V., Qureshi, Q. \& Gopal, R. (2011) Can the abundance of tigers be assessed from their signs? Journal of Applied Ecology, 48, 14-24.

Johnson, C., Crowther, M., Dickman, C., Letnic, M., Newsome, T., Nimmo, D., Ritchie, E. \& Wallach, A. (2014) Experiments in no-impact control of dingoes: comment on Allen et al. 2013. Frontiers in Zoology, 11, 17.

Johnson, C.N. \& VanDerWal, J. (2009) Evidence that dingoes limit abundance of a mesopredator in eastern Australian forests. Journal of Applied Ecology, 46, 641-646.

Karanth, K.U., Nichols, J.D., Seidenstricker, J., Dinerstein, E., Smith, J.L.D., McDougal, C., Johnsingh, A.J.T., Chundawat, R.S. \& Thapar, V. (2003) Science deficiency in conservation practice: the monitoring of tiger populations in India. Animal Conservation, 6, 141-146.

Kellner, K.F. \& Swihart, R.K. (2014) Accounting for imperfect detection in ecology: a quantitative review. PLOS ONE, 9, e111436.

Larrucea, E.S., Brussard, P.F., Jaeger, M.M. \& Barret, R.H. (2007) Cameras, coyotes, and the assumption of equal detectability. Journal of Wildlife Management, 71, 1682-1689.

Long, R.A., MacKay, P., Ray, J.C. \& Zielinski, W.J. (2008) Noninvasive Survey Methods for Carnivores. Island Press, New York.

MacKenzie, D.I., Nichols, J.D., Royle, J.A., Pollock, K.H. \& Bailey, L.L. (2006) Occupancy Estimation and Modelling: Inferring Patterns and Dynamics of Species Occurrence. Elsevier, London, U.K.

Midlane, N., O'Riain, M.J., Balme, G.A. \& Hunter, L.T.B. (2015) To track or to call: comparing methods for estimating population abundance of African lions Panthera leo in Kafue National Park. Biodiversity and Conservation, in press.

Moseby, K.E., Neilly, H., Read, J.L. \& Crisp, H. (2012) Interactions between a top order predator and exotic mesopredators in the Australian rangelands. International Journal of Ecology, 250352, 15.

This article is protected by copyright. All rights reserved. 
Nimmo, D., Watson, S., Forsyth, D.M. \& Bradshaw, C.J.A. (2015) Dingoes can help conserve wildlife and practitioners can tell. Journal of Applied Ecology, In press.

Possingham, H.P., Jarman, P. \& Kearns, A. (2004) Independent review of Western Shield February 2003. Conservation Science Western Australia, 5, 2-11.

Rotella, J.J. \& Ratti, J.T. (1992) Mallard Brood Movements and Wetland Selection in Southwestern Manitoba. The Journal of Wildlife Management, 56, 508-515.

Rowcliffe, J.M., Field, J., Turvey, S.T. \& Carbone, C. (2008) Estimating animal density using camera traps without the need for individual recognition. Journal of Applied Ecology, 45, 1228-1236.

Stander, P.E., Ghau, Tsisaba, D. \& Ui (1997) Tracking and the interpretation of spoor: a scientifically sound method in ecology. Journal of Zoology, 242, 329-341.

Stanley, T.R. \& Bart, J. (1991) Effects of Roadside Habitat and Fox Density on a Snow Track Survey for Foxes in Ohio. Ohio Journal of Science, 91, 186-190.

Stephens, P.A., Pettorelli, N., Barlow, J., Whittingham, M.J. \& Cadotte, M.W. (2015) Management by proxy? The use of indices in applied ecology. Journal of Applied Ecology, 52, 1-6.

Thurber, J.M., Peterson, R.O., Drummer, T.D. \& Thomasma, S.A. (1994) Gray wolf response to refuge boundaries and roads in Alaska. Wildlife Society Bulletin, 22, 61-68.

Whittington-Jones, B.M., Parker, D.M., Bernard, R.T.F. \& Davies-Mostert, H.T. (2014) Habitat selection by transient African wild dogs (Lycaon pictus) in northern KwaZulu-Natal, South Africa : implications for range expansion., pp. 135-147.

Whittington, J., St. Clair, C.C. \& Mercer, G. (2005) Spatial responses of wolves to roads and trails in mountain valleys. Ecological Applications, 15, 543-553.

Williams, B.K., Nichols, J.D. \& Conroy, M.J. (2002) Analysis and Management of Animal Populations. Academic Press, San Diego, California, USA.

Wilson, G.J. \& Delahay, R.J. (2001) A review of methods to estimate the abundance of terrestrial carnivores using field signs and observation. Wildlife Research, 28, 151164.

This article is protected by copyright. All rights reserved. 